\title{
Review and Survey of Broadband Techniques of Microstrip Patch Antenna
}

\author{
Tej Raj \\ M Tech. Scholar \\ DIT Dehradun
}

\author{
Brijlata Chauhan \\ Astt. Professor \\ DIT Dehradun
}

\begin{abstract}
In today communication Cellular mobile and other communication devices are getting smaller in size but the operation is held by such devices are needed much higher bandwidth. Microstrip antennas are smaller in size but having drawback of low bandwidth. Literature shows that the leading work on MSA is focused on designing compact sized broadband antenna. Last few years many bandwidth enhancement techniques have been developed. In this paper broad banding techniques of MSA have been studied and comparative analysis is done.
\end{abstract}

\section{INTRODUCTION}

As per today communication due to smaller device sizes it is needed to design the MSA which has compact in size and bandwidth is greater. But as the size of antenna is reduced the bandwidth of antenna is also decreased. Many enhancement techniques for bandwidth of MSA has been engaged now a days by keeping size compact so this low profile and narrowband antenna can be utilized for such communication with ease.

Generally MSA suffers with low bandwidth and it is 1-4\% [1] but today communication needed higher bandwidth.

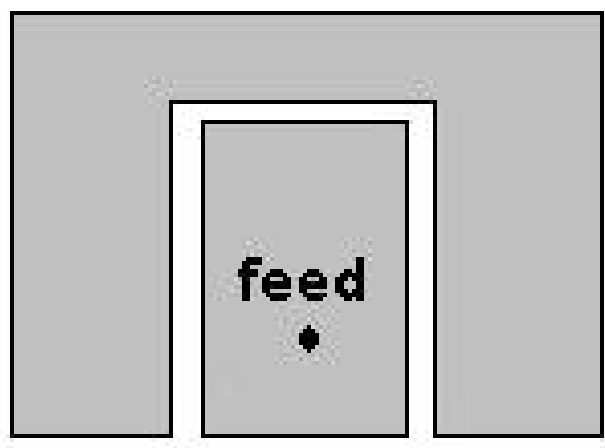

Fig 1 (a) u-slot in rectangular patch

In [6] wide band E-shaped slot is cut in the rectangular patch which achieves the total bandwidth of $30.3 \%$. In [3] a u slot is cut in the patch and optimized $26 \%$ of impedance bandwidth is achieved.

\subsection{Multiresonator MSA}

In this technique additional resonator is used to enhance the bandwidth of antenna. By using additional microstrip patches directly coupled to the radiating or non-radiating edges of a rectangular microstrip antenna, a broadband microstrip antenna can be achieved. For such a design, a rectangular microstrip antenna with two additional patches directly coupled to its radiating edges, the impedance bandwidth can
Advantage of MSA makes them suitable for numerous applications like GSM band (890-925MHz), GPS System, DCS (1710-1880 MHz), UMTS band (1920-2170 MHz), Wimax band [2] etc. For these applications to achieve required bandwidth many techniques are used and some of them are explained in this review paper.

\section{BROADBAND TECHNIQUES OF MSA}

\subsection{Slot loaded Patch}

As the simple Microstrip antenna has low bandwidth, one technique to improve this is done by cut a slot in the patch of half wavelength long at desired resonant frequency [3]. Slots are embedded in the printed patch. Their dimensions and positions are properly selected in order to the first two broadside-radiation modes of the patch be perturbed such that their resonance frequencies get close to each other to form a wide impedance bandwidth[4,5]. Slots cut into the patch are of different types e.g. commonly used slot are u-slot, E-slot $\mathrm{H}$-Slot etc. shown in figure 1(a) and 1(b).

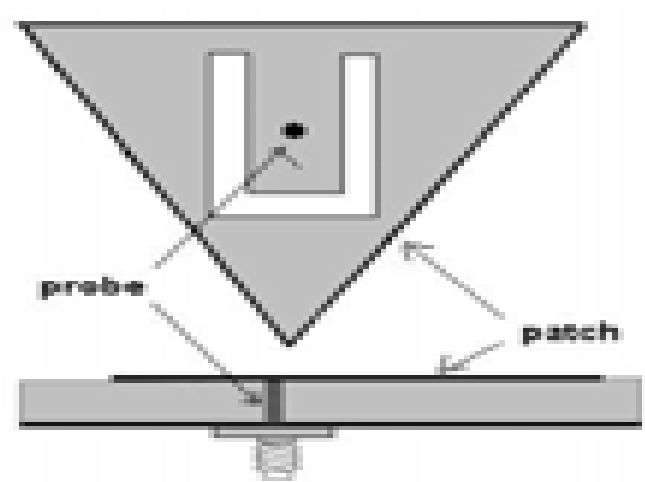

1(b) u-slot in the triangular patch.

be five times that of a single rectangular microstrip antenna [7,8].In [9] wideband u-shaped parasitic elements are incorporated into radiating edges of a rectangular patch. Antenna is fabricated on FR4 substrate shows an impedance bandwidth of $27.3 \%$ shown in fig 2.Another configuration of inverted-L- and T-shaped parasitic elements at both the radiating apertures of a microstrip patch antenna [10] shown in fig 3. In this configuration proposed antenna covers the triple band at LTE TDD No. 34 (2.0175 GHz), WLAN $(2.45$ $\mathrm{GHz})$, and WiMAX (3.5 GHz) bands. Resonance occurs in the parasitic patches due to the perturbation and electromagnetic coupling. 


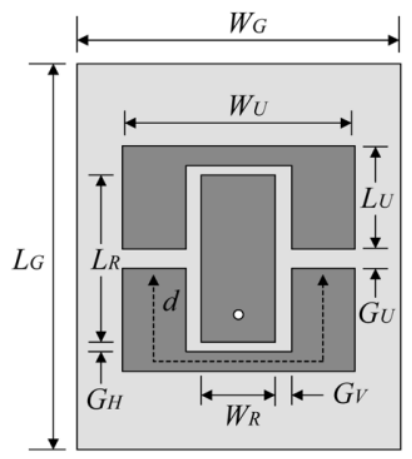

Fig 2. U-shaped parasitic elements [9]

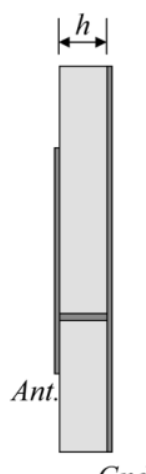

Gnd.
In [11] another configuration of directly coupled and indirectly coupled patches has been constructed and designed. The impedance bandwidth of $12.7 \%$ i.e. $365 \mathrm{MHz}$ at center frequency $2879 \mathrm{MHz}$ is obtained with $10 \mathrm{~dB}$ return loss. Without using direct coupling and indirect coupling bandwidth $2 \%$ has been achieved. Using coupling of parasitic and direct patches impedance bandwidth has $12 \%$ achieved.

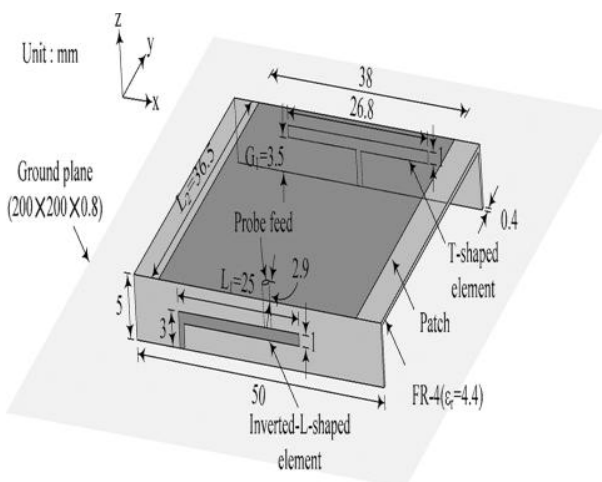

More than 6 times of bandwidth is obtained for proposed antenna. Geometry of antenna is shown in figure 4. From the above results we can conclude that using directly coupled or parasitic patches impedance bandwidth can be enhanced. Size of antenna may be bigger using parasitic patches but resulting bandwidth of such configuration is higher than single patch.

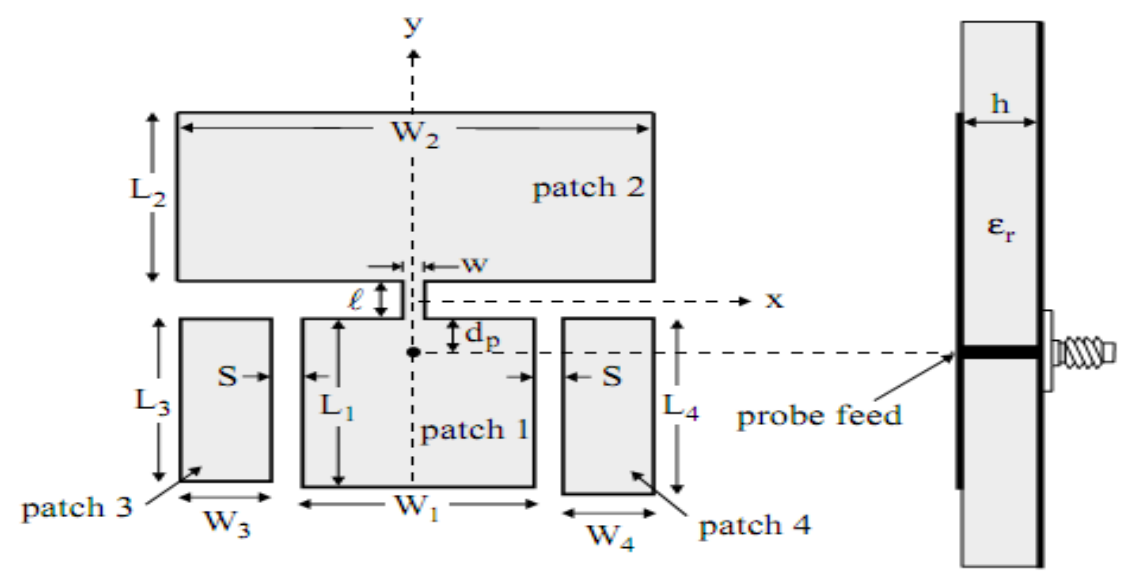

Figure 4: Proposed geometry of multi-resonator patch antenna [11]

For a Microstrip antenna edges along the width and length are known as radiating and non radiating edged respectively. When a patch is placed close to the active patch, gets excited through the coupling between the patches. If the resonances of the both patch are close to each other broad bandwidth is achieved. The parasitic patches are used in the different combination e.g. gap coupled single patch, gap coupled two equal patches along the radiating or non radiating edge of a active patch. When parasitic patch on one of the radiating edge is placed it results in broad bandwidth but leads to shift the beam maxima from $\Theta=45$ degree and pattern is no symmetrical along broadside direction [1]. To obtain the symmetrical pattern along broadside direction two equal gap coupled parasitic patches is used on the both of radiating edges. Symmetrical pattern is obtained because of the both parasitic patches shift the pattern in $+\Theta$ and $-\Theta$ so net effect is zero. Also the length of two parasitic patches can be chosen different so it generates the three resonant frequencies. It certainly leads to shift of beam maxima but still this change is acceptable. Parasitic patches can also be placed along the non radiating edges of the active patch. Similarly the four gap coupled patches can used also used to enhance the bandwidth of microstrip antenna. The active patch should be designed so that $f_{1}=f_{L}+\Delta f$ with bandwidth of $\Delta f$ [1]. Length of patches is chosen so that $f_{2}=f_{H^{-}}-\Delta f$. Gap between active and parasitic patch is mainly depend upon the height of substrate (h) and dielectric constant $\left(\xi_{\mathrm{r}}\right)$. If the spacing is small leads to increase the VSWR $=2$ circle. Maximum gap between the radiating edges is $0.8 \mathrm{~h}$ and $0.3 \mathrm{~h}$ at non radiating edges.

\subsection{Multilayer broadband MSA}

Multilayer structure MSA more than one patch is stacked on substrate of different layer. The overall height of the antenna is increased but size in planner direction is remaining similar. Two coupling techniques are used in layered structure 1 . Electromagnetic coupled MSA 2. Aperture coupled MSA [1]. Using multilayer structure yield impedance bandwidth of $114 \%$ [12] has been achieved. In [12] MSA has implemented using patch and parasitic radiating element on a stacked FR4 substrate. Parasitic patches are optimized to produce two resonances within central location of frequency band 3-11 GHz. Figure 5 shows the geometry of antenna. In this structure the additional c-slot is introduced in ground plane and then optimized with E-slot on the parasitic patch which 
enhances the bandwidth more. Antenna gain is about $12 \mathrm{~dB}$ is obtained at center frequency $7 \mathrm{GHZ}$. There are two types of electromagnetically coupled MSA shown in fig. 6(a) and 6(b) bottom patch is fed with coaxial cable and upper patch is excited due to coupling. Patches can be fabricated on a different substrate and air gap is also introduced between the layers.

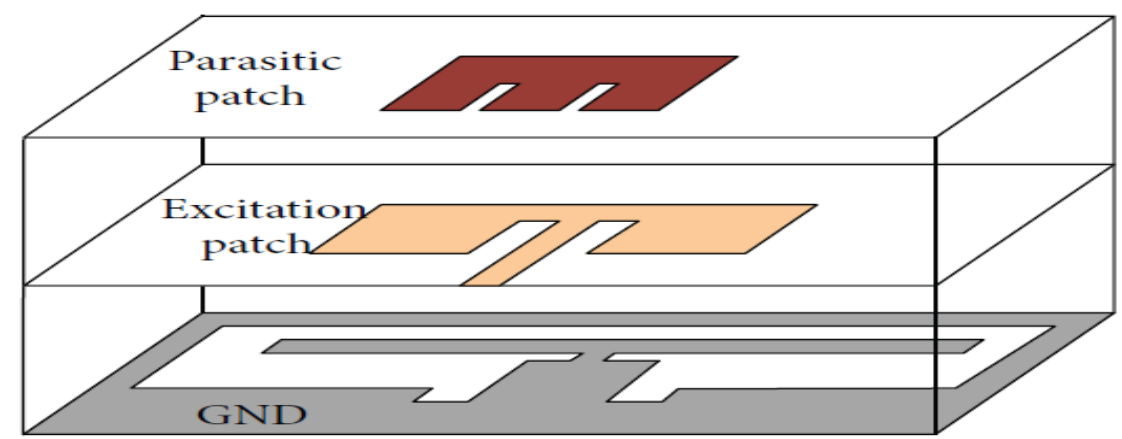

Figure 5: Proposed geometry of stacked patch antenna [12]

With the use of layered structure the parasitic patches are optimized to obtain the broad bandwidth [13-19]. The effect of the length of upper patch and lower patch in the stacked configuration is very important to remain the VSWR $=2$ circle. For wide bandwidth and gain requirement the value of air gap is chosen accordingly. For different value of $\Delta$ (air gap) bandwidth is increase and decrease given in [20]. Another techniques to enhance the Microstrip antenna is aperture coupled MSA which yield a bandwidth of $70 \%$ given in [21]. ACMSA consist of two substrate separated by a ground plane and an aperture is cut in the ground plane that Electromagnetically coupled the upper patch with the Microstrip line feed on the lower substrate. Aperture is cut in the ground plane at the centre location of the patch to provide the maximum coupling and symmetrical radiation pattern. Advantages of such configuration are that patch is fabricated on the top patch that enhances the BW and feed line is at the lower substrate that reduces the radiation losses.
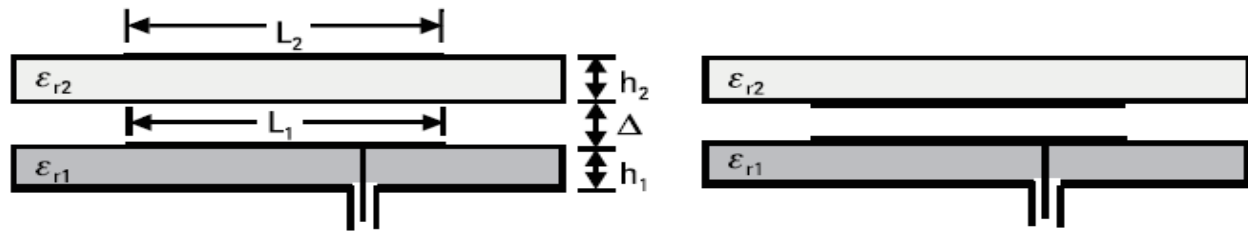

Figure 6(a) Electromagnetically coupled MSA normal geometry 6(b) Inverted geometry

Another techniques to enhance the Microstrip antenna is aperture coupled MSA which yield a bandwidth of $70 \%$ given in [21]. ACMSA consist of two substrate separated by a ground plane and an aperture is cut in the ground plane that Electromagnetically coupled the upper patch with the Microstrip line feed on the lower substrate. Aperture is cut in the ground plane at the centre location of the patch to provide the maximum coupling and symmetrical radiation pattern. Advantages of such configuration are that patch is fabricated on the top patch that enhances the BW and feed line is at the lower substrate that reduces the radiation losses. The performance of ACMSA depends on the various parameters like aperture dimensions patch dimensions and feed network and thickness of the substrate. Geometry of ACMSA is shown in figure 7. In [22] a ACMSA is analyzed for various parameter. Aperture dimensions are plays an important role. If the slot is large then the more coupling that leads to increase the input impedance but slot length is small then the coupling is less that leads to less input impedance. Therefore to get resistive impedance, slot dimensions are optimized to get desired results. Except the aperture dimensions, location of aperture length and width of patch are discussed and analyzed in the [22-25]. 


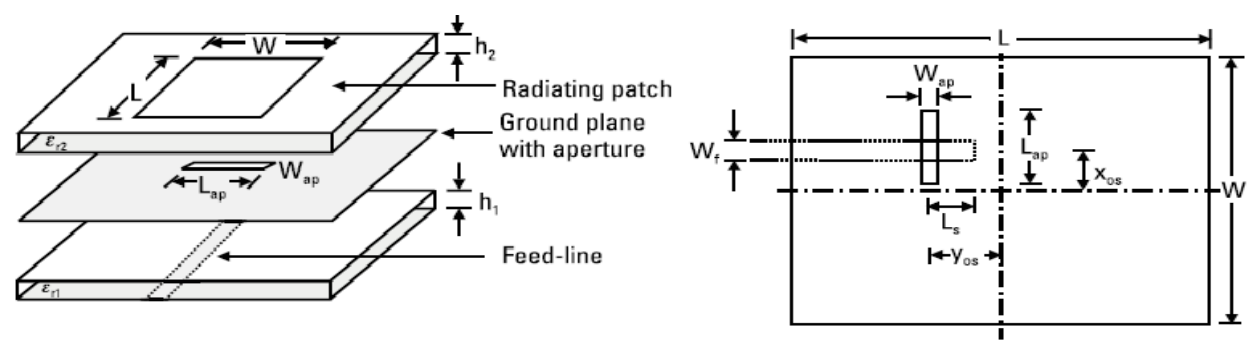

Figure 8: ACMSA: (a) exploded and (b) top views.

\section{COMPARATIVE ANALYSIS OF BROADBAND TECHNIQUES}

\begin{tabular}{|c|c|c|c|}
\hline S.N & Broadband techniques & Configuration & Remarks \\
\hline \multirow[t]{2}{*}{1.} & \multirow[t]{2}{*}{ Slot loaded techniques } & Rectangular patch E-shaped slot[6] & $26 \%$ of bandwidth is achieved. \\
\hline & & u-slot Rectangular patch[3] & $26.09 \%$ bandwidth is achieved. \\
\hline \multirow[t]{3}{*}{2.} & \multirow[t]{3}{*}{ Multiresonator Techniques } & $\begin{array}{l}\text { Wideband u-shaped parasitic } \\
\text { elements[9] }\end{array}$ & $27 \%$ bandwidth is achieved. \\
\hline & & $\begin{array}{l}\text { Microstrip Antenna Using Inverted-L- } \\
\text { and T-Shaped Parasitic Elements[10] }\end{array}$ & $\begin{array}{l}\text { 10-dB bandwidths cover the required } \\
\text { bandwidths at } 28 \mathrm{MHz}(1.39 \%), 91 \mathrm{MHz} \\
(3.71 \%) \text {, and } 255 \mathrm{MHz}(7.29 \%) \text {. Within } \\
\text { each of the designed bands, a broadside } \\
\text { Radiation pattern is observed. }\end{array}$ \\
\hline & & $\begin{array}{l}\text { Directly and non directly coupled } \\
\text { patches[11] }\end{array}$ & $\begin{array}{l}\text { The impedance bandwidth of } 12.7 \% \text { is } \\
\text { achieved which is six times more than } \\
\text { normal patch. }\end{array}$ \\
\hline \multirow[t]{3}{*}{3.} & \multirow[t]{3}{*}{ Multilayer Structure } & $\begin{array}{l}\text { With parasitic patch and defective } \\
\text { ground[12] }\end{array}$ & $\begin{array}{l}\text { Impedance bandwidth of } 114 \% \text { is } \\
\text { achieved. }\end{array}$ \\
\hline & & Aperture coupled MSA[21] & Impedance bandwidth of $70 \%$ is achieved. \\
\hline & & $\begin{array}{l}\text { U-shaped microstrip patch antenna with } \\
\text { novel parasitic tuning stubs[26] }\end{array}$ & $\begin{array}{l}\text { Impedance bandwidth of } 129 \% \text { is achieved } \\
\text { with gain } 1.6 \text { to } 5.3 \mathrm{dBi} \text { against frequency. }\end{array}$ \\
\hline
\end{tabular}

\section{CONCLUSION}

Narrow bandwidth is always a constraint on MSA. So different broadband techniques are used to enhance the it. In this paper some of these techniques are reviewed and discussed. Out of all techniques Multilayer structure yields a maximum bandwidth. But it also increases the size of antenna as well due to more than one patch. Also slot loaded techniques is provides the bandwidth enhancement up to $30 \%$ which has an advantage of size of antenna is remain small. 


\section{REFRENCES}

[1] Girish Kumar and K.P. Ray, "Broadband microstrip antennas", Artech House antennas and propagation library, page number: 14, 89-90, ISBN 1-58053-244-6, 2003.

[2] Kin-Lu Wong, "Compact and Broadband Microstrip Antennas", John Wiley \& Sons, page number: 12-14, ISBNs: 0-471-41717-3, 2002.

[3] Sanjeev Kumar Sharma and Munish Rattan "Analysis of Broad Banding and Minimization Techniques for Square Patch Antenna" IETE journal of research vol 56 issue 2 mar-apr 2010.

[4] K.W. Loi, S. Uysal, and M. S. Leong, "Design of a wideband Microstrip bowtie patch antenna" Proc. Inst. Elect. Eng. Microwave Antennas propagation vol. no. 145,pp. 137-140, 1998.

[5] Shing-Lung Steven Yang, Ahmed A. Kishk , and KaiFong Lee "Frequency Reconfigurable U-slot Microstrip Antenna" IEEE antenna and wireless propagation letters vol. no. 7, 2008 .

[6] Fan Yang, Xue-Xia Zhang,Xiaoning Ye, Yaha Rahmat Samii "Wide band E- shaped patch antennas for wireless communications" IEEE transactions on antennas and propagation, vol. 49, no. 7, July 2001.

[7] G. Kumar and K. C. Gupta, "Broad-band Microstrip antennas using additional resonators gap-coupled to the radiating edges," IEEE Trans. Antennas Propag., vol. AP-32, pp. 1375-1379, Dec. 1984.

[8] "Nonradiating edges and four edges gap-coupled multiple resonator broad-band Microstrip antennas," IEEE Trans. Antennas Propag., vol. AP-33, pp. 173-178, Feb. 1985.

[9] Sang-Hyuk Wi, Yong-Shik Lee, and Jong-Gwan Yook "Wideband Microstrip Patch Antenna With U-Shaped Parasitic Elements" IEEE transactions on antennas and propagation, vol. 55, no. 4, April 2007.

[10] Girish Kumar and K.P. Ray, "Stacked gap-coupled multiresonator rectangular Microstrip antennas", Antennas and Propagation Society International Symposium, IEEE Vol. 3, ISBN 0-7803-7070-8, page number: $514-517$, Aug. 7, 2002.

[11] C. K. Wu and K. L. Wong, "Broadband microstrip antenna with directly coupled and gap-coupled parasitic patches", Microwave Opt. Technol. Lett. 22, 348-349, Sept. 5, 1999.

[12] Sharif I.Mitu Sheikh, W. Abu-Al-Saud, and A. B. Numan"Directive Stacked Patch Antenna for UWB Applications" Hindawi Publishing Corporation International Journal of Antennas and Propagation Volume 2013, Article ID 389571, 6 pages http://dx.doi.org/10.1155/2013/389571
[13] James, J. R., and P. S. Hall, Handbook of Microstrip Antennas, Vol. 1, London: Peter Peregrinus, Ltd., 1989.

[14] Gupta, K. C, and A. Bennella, Microstrip Antennas Theory and Design, Norwood, MA: Artech House, 1988.

[15] Pozar, D. M., and D. H. Schaubert, Microstrip Antennas: The Analysis and Design of Microstrip Antennas and Arrays, New York: IEEE Press, 1995.

[16] Sainati, R. A., CAD of Microstrip Antennas for Wireless Applications, Norwood, MA: Artech House, 1996.

[17] Lee, H. F., and W. Chen, Advances in Microstrip and Printed Antennas, New York: John Wiley \& Sons, Inc. 1997.

[18] Damiano, J. P., J. Bennegueouche, and A. Papiernik, "Study of Multilayer Antennas with Radiating Elements of Various Geometry," Proc. IEE, Microwaves, Antennas Propagation, Pt. H, Vol. 137, No. 3, 1990, pp. 163-170.

[19] Sabban, A. "A New Broadband Stacked Two Layer Microstrip Antenna,” IEEE AP-S Int. Symp. Digest, June 1983, pp. 63-66. Lee, R. Q., and K. F. Lee, "Experimental Study of the Two-Layer Electromagnetically.

[20] Coupled Rectangular Patch Antenna," IEEE Trans. Antennas Propagation, Vol. AP-38, August 1990, pp. 1298-1302.

[21] Pozar, D. M., "Microstrip Antenna Aperture Coupled to a Microstrip Line," Electronics Letters, Vol. 21, No. 2, 1985, pp. 49-50.

[22] Sullivan, P. L., and D. H. Schaubert, "Analysis of an Aperture-Coupled Microstrip Antenna,' IEEE Trans. Antennas Propagation, Vol. AP-34, No. 8, 1986, pp. 977-984.

[23] El Yazidi, M., M. Himdi, and J. P. Daniel, "Transmission Line Analysis of Nonlinear Slot-Coupled Microstrip Antennas," Electronics Letters, Vol. 28, 1992, pp. 1406-1408.

[24] Pozar, D. M., and S. D. Targonski, "Improved Coupling for Aperture Coupled Microstrip Antennas," Electronics Letters, Vol. 27, No. 13, June 1991, pp. 1129-1131.

[25] Rathi, V., G. Kumar, and K. P. Ray, "Improved Coupling for Aperture Coupled Microstrip Antennas,' IEEE Trans. Antennas Propagation, Vol. AP-44, No. 8, 1996,pp. 1196-1198.

[26] M. Koohestani, M. Golpour "U-shaped microstrip patch antenna with novel parasitic tuning stubs for ultra wideband applications" IET Microw. Antennas Propag., 2010, Vol. 4, Iss. 7, pp. 938-946. 